\title{
Perspectives on the application of biotechnology to assist the genetic enhancement of plantain and banana (Musa spp.)
}

\author{
Jonathan H. Crouch \\ Elsoms Seeds Ltd., Spalding, Lincolnshire, PE11 1QG, England, United Kingdom. \\ E-mail: crouch@globalnet.co.uk \\ Dirk Vuylsteke \\ International Institute of Tropical Agriculture (IITA), East and Southern Africa Regional Centre (ESARC), P.O. Box 7878, Kampala, Uganda. \\ E-mail: iita@imul.com \\ Rodomiro Ortiz ${ }^{1}$ \\ The Royal Veterinary and Agricultural University (KVL), Department of Agricultural Sciences, 40 Thorvaldsensvej, DK-1871 Frederiksberg C, Copenhagen, Denmark. \\ E-mail:ro@kvl.dk
}

International Institute of Tropical Agriculture, PMB 5320, Oyo Road, Ibadan, Nigeria

\begin{abstract}
Bananas and plantains (Musa spp.) are the most important tropical fruit crops. They form an integral component of the farming systems in the humid agroecological zones of the tropics. A broad array of applied cell and molecular techniques are increasingly being used worldwide to facilitate and enhance the handling and improvement of plantain and banana germplasm. Tissue culture is used for germplasm exchange, conservation and rapid multiplication, while in vitro seed germination (based on embryo culture or rescue) plays a critical role in generating hybrid plants. DNA marker systems have been developed in Musa to assist germplasm management, selection within the breeding pool or gene introgression from wild species, and for disease diagnosis. Likewise, genetic transformation using the particle gun method or through Agrobacterium co-cultivation shows potential for the genetic betterment of the crop. This article discusses the applications of biotechnology for the genetic enhancement of banana and plantain. It highlights current advances by research teams across the world and reviews progress in molecular breeding of Musa by the International Institute of Tropical Agriculture and its collaborators.
\end{abstract}

Plantains and bananas (Musa spp.) are staple foods for rural and urban consumers in the humid tropics and an important source of rural income, particularly in some locations where smallholders produce them in compound or home gardens. World Musa production is around 85.5 million tonnes annually (FAO 1998), of which bananas cultivated for the export trade account for only $10 \%$. Hence, fruit harvested from bananas and plantains are important components of food security in the tropical world, and provide income to the farming community through local and international trade.

Most banana cultivars and all plantain landraces have 33 chromosomes $(2 \mathrm{n}=3 \mathrm{x})$. These triploid genotypes are virtually or completely sterile and develop their fruit by vegetative parthenocarpy. Diploid landraces and tetraploid cultivars (mostly artificial hybrids) are also cultivated. The evolution of Musa cultivars from their wild species ( $M$. acuminata Colla. and $M$. balbisiana Colla.), and their dispersal from the southeast Asian centre of origin to the new secondary centres of diversity, has been documented in detail (Simmonds 1962). For example, recurrent somatic mutations followed by human selection for their tasty fruit led to great phenotypic diversity amongst plantain landraces in the humid lowlands of West Africa, and amongst beer and cooking bananas in the highlands of East Africa.

Many pests and diseases have significantly affected Musa cultivation. More virulent fungal strains of Fusarium oxysporum Schlecht f. sp. cubense (E.F. Smith) Snyd \& Hans (Panama disease or wilt), and Mycosphaerella fijiensis Morelet (black Sigatoka) have spread dramatically during the past 20 years. As a consequence of these threats to Musa cultivation, there has been renewed interest in Musa breeding programs. Although some programs have addressed improvement of export bananas, generally the goal has been to improve cultivars for local consumption in the tropical world (Ortiz and Vuylsteke 1996). Musa breeders face many problems intrinsic to this crop that slow the genetic improvement of bananas and plantains, viz. low fertility due to triploidy, slow propagation, long time span from one generation to the next (almost two years from seed to seed), and a large area requirement for field testing $\left(6 \mathrm{~m}^{2}\right.$ per plant). Some of these obstacles have been overcome through conventional methods by screening for seed-fertility, and through ploidy manipulations and interspecific hybridization (Rowe and Rosales 1996; Vuylsteke et al. 1997). Likewise, routine biotechniques such as in vitro germination of seeds and rapid micropropagation for station trials have allowed more rapid breeding progress in bananas and plantains. More recently, successful cross breeding programs are adopting emerging biotechniques such as genetic engineering and molecular marker-assisted breeding to enhance the effectiveness of their operations.

This paper reviews the achievements and advances in the application of tissue culture and molecular biology to assist the genetic enhancement of Musa. We also highlight the current work in molecular breeding at the International 
Institute of Tropical Agriculture (IITA) and discuss the potential of such approaches for the development of new banana and plantain cultivars.

\section{Micropropagation}

In vitro propagation has many advantages, such as higher rates of multiplying clean (pest and disease-free) planting material and the small amount of space required to multiply large numbers of plants. Micropropagation techniques were developed during the past two decades and are now well established (Banerjee and De Langhe 1985; Cronauer and Krikorian 1984; Israeli et al. 1995; Vuylsteke 1989). Tissue culture labs supply the regular replanting needs of the large export banana plantations (Smith and Drew 1990a). Shoottip culture is simple, easy, and applicable to a wide range Musa genotypes (Vuylsteke 1989). Multiple shoot or bud formation is easily achieved by culturing shoot tips on standard nutrient media containing 2-5 mg. $\mathrm{l}^{-1}$ cytokinin (mostly 6-benzylaminopurine) or by incising or fragmenting the shoot tips. Rates of multiplication range from two to ten or more shoots or bud propagules per month, resulting in potential propagation rates of several thousands or millions of plants per year. Such rates are several orders of magnitude greater than achievable through conventional propagation.

Application of micropropagation has greatly improved Musa germplasm handling for the purposes of clonal propagation, uniform production, and breeding.

Micropropagation has played a key role in plantain and banana improvement programs worldwide (Rowe and Rosales 1996; Vuylsteke et al. 1997).

Planting material derived from micropropagation performs equal to or superior to conventional material (Smith and Drew 1990a; Vuylsteke 1998). Micropropagated plants establish faster, grow more vigorously, are taller, have a shorter and more uniform production cycle, and yield higher than conventional propagules (Drew and Smith 1990; Robinson et al. 1993; Vuylsteke and Ortiz 1996). Maximum yield gains from in vitro derived plants range from $20 \%$ in bananas to $70 \%$ in plantains. However, this superior field performance does not appear to be consistent and requires optimal crop husbandry (Vuylsteke 1998).

\section{Other tissue culture applications}

In vitro culture for germplasm exchange and conservation, in vitro germination of seeds through embryo culture, cryopreservation, and cell suspensions also have important applications in Musa breeding.

\section{Germplasm exchange and conservation}

Shoot-tip culture, combined with third-country quarantine (Vuylsteke et al. 1990a) or virus indexing (Diekmann and Putter 1996), is a means for the safe exchange of Musa germplasm. This methodology reduced volume and weight compared to conventional propagules and improves the phytosanitary status of germplasm. Virus testing of germplasm is now recommended as a routine procedure to ensure its safe international distribution, because many viruses affecting Musa are not eliminated by tissue culture (Drew et al. 1989).
Shoot-tip cultures maintained at lower temperatures (15$18^{\circ} \mathrm{C}$ ) have been used for the slow-growth storage of Musa germplasm (Banerjee and De Langhe 1985; Van den houwe et al. 1995). A simple technique was recently developed for cryopreservation of meristem cultures, which involves preculture on high-sucrose medium followed by rapid freezing (Panis et al. 1996).

\section{Embryo culture}

Low seed set and low seed viability are major constraints to many aspects of Musa breeding. Embryo culture was the first application of a tissue culture technique in Musa nearly 40 years ago (Cox et al. 1960). Axenic in vitro germination of hybrid seed has been a cornerstone of Musa breeding programs. Indeed, embryo culture increases rates of seed germination by a factor of 10 or more (Vuylsteke et al. 1990b).

\section{Cell suspension and protoplast culture}

Plant regeneration from callus or by direct somatic embryogenesis in cell suspensions or protoplasts was investigated for its potential in mass propagation and as a tool in transformation using recombinant DNA technology. It has been achieved in cell or protoplast cultures derived from in vitro meristems (Novak et al. 1989; Dhed'a et al. 1991; Panis et al. 1993), immature zygotic embryos (Escalant and Teisson 1989) and young male flower tissue (Ma 1988; Escalant et al. 1993). However, most of these procedures are still laborious and success is genotype-specific.

\section{Somaclonal variation}

Genetic variation resulting from micropropagation, i.e., somaclonal variation, appears to be ubiquitous in Musa. The frequent occurrence of somaclonal variation in Musa has warranted investigations into its nature and extent. Rates of somaclonal variation in plants derived from shoot-tip culture vary from 0 to $70 \%$ according to genotype (Israeli et al. 1995; Smith 1988; Vuylsteke et al. 1991). This genetic instability may be a risk associated with the application of in vitro culture techniques for germplasm handling and storage. Conversely, somaclonal variation may provide another source of novel and useful variability (Vuylsteke 1998), though most somaclonal variants recovered through shoot-tip culture exhibit naturally occurring variation or defective phenotypes (Israeli et al. 1995; Smith 1988; Vuylsteke et al. 1991). Dwarfism in 'Cavendish' bananas or inflorescence variation in plantains are often observed after micropropagation of respective mother genotypes. Furthermore, most variants are mostly inferior to the original cultivar from which they were derived. For example, bunch and fruit of these variants are often smaller (Smith and Drew 1990b; Vuylsteke et al. 1996), thereby offsetting the potential benefits of variants with putative disease resistance. Somaclonal variation has so far had a limited direct contribution to the genetic enhancement of Musa. However, somaclonal variation arising from shoot micropropagation may only represent a fraction of the variation that may be generated through regeneration from cell and protoplast cultures of different explants. Thus, the full potential of somaclonal variation for Musa improvement should be explored. Ultimately, the value of somaclonal variation in breeding lies in the capacity to obtain at high frequency genetic variants with the desired characteristics. 
Consequently, it would be useful to devise methods to identify rare but useful somaclonal variants among large populations of useless variants. Somaclonal variation may also provide a means to utilize otherwise inaccessible genepools, e.g., increased female fertility in a variant derived from an almost sterile False Horn plantain made this sterile plantain pool amenable to conventional breeding schemes (Vuylsteke et al. 1995; Vuylsteke 1998).

\section{Transgenic Musa}

Asexual gene transfer methods such as transformation may be required for characteristics lacking in Musa genebanks, or for the genetic improvement of cultivars not amenable to conventional cross breeding such as Cavendish bananas or Horn plantains. Relative success in genetic engineering of bananas and plantains has been achieved recently to enable the transfer of foreign genes into plant cells. Protocols for electroporation of protoplasts derived from embryogenic cell suspensions (Sagi et al. 1994), particle bombardment of embryogenic cells (Sagi et al. 1995), and co-cultivation of wounded meristems with Agrobacterium (May et al. 1995) are available for bananas and plantains. The latter system may be more widely applicable as it is based on the use of differentiated tissue that can be routinely regenerated into whole plants. In addition, it has been applied to a range of plantain and banana cultivars and synthetic hybrids (BosquePérez et al. 1998). Genes coding for antifungal proteins that show broad antifungal activity in vitro have been introduced into a plantain landrace and the resulting transgenic plants await field testing (Remy et al., 1998).

Transformation of sterile triploid dessert banana cultivars could certainly have a significant commercial impact. A new transgenic banana cultivar may be released to the market within six years. For example, DNA Plant Technology Corporation has been developing bananas with extended shelf- life (NCGR, 1998). Researchers are using the ripening control technology that consists of suppressing production of ethylene, the hormone that induces fruit ripening. This technology has been successfully applied earlier by this company in the development of the transgenic Endless Summer $^{\mathrm{TM}}$ tomato. Similarly, scientists at Zeneca Plant Sciences are developing resistance to black Sigatoka and modifying ripening characteristics in banana. Success in these endeavours will lessen the required fungicide inputs for banana cultivation, and will improve fruit shelf-life in the markets.

\section{DNA markers}

Considerable attempts have been made to distinguish and classify Musa accessions on the basis of morphological characteristics (Simmonds and Shepherd 1955). However, the classification of certain accessions on this basis has been disputed (Gawel and Jarret 1991a, b). Isozymes (Bonner et al. 1974; Jarret and Litz 1986; Bhat et al. 1992a, b; Lebot et al. 1993) and other biochemical markers (Horry and Jay 1988) have been used to study diversity in Musa. Yet, biochemical markers are not sufficiently abundant or polymorphic to form the basis of a comprehensive marker assisted breeding system.

Restriction fragment length polymorphisms (RFLP) of diverse germplasm have been used to study the taxonomy and phylogeny of Musa species (Jarret et al. 1992; Gawel et al. 1992; Lanaud et al. 1992; Carreel et al. 1994, Jenny et al. 1997), and variation in the chloroplast genome within the Musa genus (Gawel and Jarret 1991b, Baurens et al. 1997). However, there is only one report of their use to distinguish more closely related material (Bhat et al. 1994). More importantly perhaps, the relatively high cost and technically demanding nature of this technique is not appropriate to routine breeding applications. Thus, researchers have concentrated on applications of the polymerase chain reaction (PCR) for Musa genome analysis.

All PCR-based molecular markers appear to detect a high level of polymorphism within a range of Musa breeding populations (J.H. Crouch, unpub. data). In addition, PCRbased assays are amenable to the large scale throughput demands of screening breeding populations. The random amplified polymorphic DNA (RAPD) technique has been successfully used to distinguish diverse Musa germplasm (Kaemmer et al. 1992; Howell et al. 1994; Bhat and Jarret 1995). In addition, a molecular linkage map has also been developed using a variety of marker systems including RAPD (Faure et al. 1993). RAPD assays are particularly useful as they require no prior knowledge of the organism. RAPD analysis has been used to differentiate Musa genome groups (Howell et al. 1994), more closely related Musa germplasm (Bhat and Jarret 1995) and full-sib hybrids in plantain breeding populations (Crouch et al. 1998a, b). These reports clearly demonstrate the potential value of this technique for germplasm characterization and cultivar identification but give little insight into the value of the assay for molecular breeding.

RAPD assays have proven to be powerful and efficient means of assisting introgression and backcross breeding. However, RAPD analysis has several disadvantages including the dominant nature of the marker system and reproducibility problems, which may limit their application in marker assisted selection (MAS). This has led to a focus on the development and utilization of primers for Musa microsatellites (Jarret et al. 1994; Kaemmer et al. 1997) which have been considered optimum markers in other systems due to their abundance, polymorphism and reliability. Microsatellites markers, otherwise known as simple sequence repeat length polymorphisms (SSRLP) are generated by highly specific PCR amplification and, therefore, should not suffer from the reproducibility problems experienced with RAPD analysis. Simple sequence repeats (SSR) are regions of short tandemly repeated DNA motifs (generally less than or equal to $4 \mathrm{bp}$ ) with an overall length in the order of tens of base pairs. SSR have been reported to be highly abundant and randomly dispersed throughout the genomes of many plant species. Variation in the number of times the motif is repeated is thought to arise through slippage errors during DNA replication. Thus, SSRLP may occur even between closely related individuals. Microsatellite markers have been used in plants for fingerprinting, mapping, and genetic analysis. SSRLP analysis has been shown to detect a high level of polymorphism between individuals of Musa breeding populations (Crouch et al. 1998b). However, the isolation of microsatellites is time consuming and expensive. Nevertheless, several hundred SSRLP markers have been generated in Musa (Jarret et al. 1994; Lagoda et al. 1995; Kaemmer et al. 1997; Crouch et al. 1998a). Furthermore, the isolation of SSR is becoming increasingly routine with the availability of automated DNA sequencing facilities, 
improved techniques for the construction of genomic libraries enriched for SSR and improved techniques for the screening of appropriate clones. This has recently allowed the rapid isolation of several hundred microsatellites from the Musa B genome (R.L. Jarret, USDA and J.H. Crouch, unpub. data).

Recently the technique of amplified fragment length polymorphism (AFLP) has been successfully applied in a variety of systems. Preliminary AFLP analysis of Musa breeding populations suggests that this technique may be a most powerful tool in the molecular breeding of plantain and banana (A. Van Gysel, Univ. Gent, unpub. data). AFLP analysis is clearly a powerful technique in terms of its ability to identify a large number of polymorphic bands without any prior knowledge of the organism. Unfortunately, the information content of these banding patterns is restricted as they must initially be treated as dominant markers. However, when AFLP analysis is applied to large populations, circumstantial allelic relationships may be sufficient for practical purposes. Software has been developed to distinguish homozygotes and heterozygotes on the basis of band intensity. Yet, such an approach may be frequently confounded by the presence of bands of intermediate intensity. AFLP assays are also technically demanding and expensive in that they require a number of DNA manipulations and a complex visualization procedure. In addition, they require relatively large amounts of reasonably high quality DNA. The use of poor quality DNA may lead to incomplete digestion which can result in artificial polymorphisms.

All marker systems have different advantages and disadvantages in specific applications. Thus, it is important for molecular breeding programs to develop capacity in several assays in order that the most suitable system can be chosen and rapidly applied for any particular application. In addition, different DNA marker assays detect (and are therefore affected by) different types of genetic variation. Thus, it is likely that the use of a range of DNA marker assays is warranted in order to generate the most accurate characterization of germplasm (Bhat et al. 1997).

\section{Cloning microsatellites from the A and B Musa genomes.}

Genomic libraries from $M$. acuminata and $M$. balbisiana accessions have been screened with a variety of repetitive oligonucleotides including $(\mathrm{GA})_{11},(\mathrm{AT})_{11},(\mathrm{CT})_{11},(\mathrm{ATT})_{10}$ and $(\mathrm{CTT})_{10}$ (Jarret et al. 1994; R.L. Jarret, USDA, unpub. data). The sequence of selected fragments was then determined and PCR primers designed from sequences flanking the SSR. More than half of the SSR isolated from M. acuminata had simple dinucleotide (GA) or (CT) core motifs (Crouch et al. 1997). No simple (AT) repeats were isolated despite their reported abundance in plant species. This is likely to be due to self-annealing of the $(\mathrm{AT})_{11}$ probe. However, several complex SSR which included (AT) motifs were isolated by virtue of their association with (GA), (AG) or (CT) motifs. In common with other genera, trinucleotide and tetranucleotide repeats appear to be less abundant in Musa than dinucleotide repeats. In this way, approximately 100 useful microsatellite markers have been generated from M. acuminata while a similar number are expected to result from parallel work on M. balbisiana. Similar microsatellite isolation projects are also ongoing at CIRAD (Lagoda et al.
1995), the University of Frankfurt (Weising et al. 1996) and the University of Saskatchewan while smaller projects have been initiated elsewhere. This is likely to result in the availability of more than 500 microsatellite markers for genetic analysis and molecular breeding in Musa.

\section{Molecular cytogenetic analysis of allopolyploids}

Although a preliminary karyotype of Musa has been reported (Dantas et al. 1993), progress in cytogenetic knowledge has been extremely slow due to the very small compact nature of Musa chromosomes. This has led to the development of flow cytometric techniques for rapid routine ploidy determination in Musa (Dolezel et al. 1994; van Duren et al. 1996). However, this approach can not generally be used for more detailed analysis. Therefore, there is considerable need for techniques that can not only be used to accurately determine the precise chromosome number but also the genomic constitution of the chromosome complement. Preliminary studies using in situ hybridization techniques have generated $\mathrm{A}$ and $\mathrm{B}$ genome-specific probes capable of determining the genomic constitution of allopolyploid Musa genotypes (Osuji et al. 1997a). This approach holds considerable scope for precisely defining the structure of allopolyploid Musa cultivars, landraces and hybrids as has been achieved in other systems. Moreover, comparative in situ hybridization studies of Musa hybrids and their parental genotypes will facilitate detailed understanding of chromosome action during interspecific and interploidy Musa hybridizations. This type of information will be enormously useful for defining and directing new Musa breeding strategies.

\section{Analysis of somaclonal variants of plantain landraces}

During field propagation of plantains and bananas, a series of consistent off-types have been observed. In the West African plantains, for example, a large number of somatic mutations affect pseudostem pigmentation, plant height, inflorescence morphology plus fruit colour and size. The stability of Musa off-types through a series of vegetative cycles suggests that they have a genetic basis (Vuylsteke et al. 1991). RAPD assays have been used for the analysis of micropropagated populations which were generated from single meristems of two plantain landraces (E.C. Howell, B.V. Ford-Lloyd and H.J. Newbury, Birmingham Univ., UK with J.H. Crouch, unpub. data). These were established in the field, morphologically characterized and subjected to intensive RAPD analysis. There was a clear correlation between the genotypic classification of individual plants (based on RAPD analysis) and the tissue culture pedigree, suggesting that a substantial amount of the variation existed within the original cultured meristem. On this basis it is hypothesized that the meristems of these accessions were sectorial chimeras. Models based on this assumption have been shown to take account of a large proportion of the observed variation.

\section{Analysis of breeding systems}

Studying the molecular genetic constitution of hybrid and parental genotypes can generate important information on which to base the development of appropriate breeding strategies. For example, SSRLP assays have been used to study the genetic behaviour during interploidy Musa crosses in order to define appropriate breeding strategies (Crouch et al. 1998a). Comparative analysis of tetraploid hybrids and 
their parental diploid and triploid genotypes indicates the occurrence of recombination during the formation of $2 \mathrm{n}(=$ $3 \mathrm{x}$ ) gametes by triploid plantain landraces. This has definitively challenged the previously held belief that plantain and banana crops are intractable to genetic improvement due to the fixed genome of triploid Musa and that polyploid Musa breeding is restricted to the development of improved diploid genotypes. Similar studies identified a substantial number of heterozygous loci in the phenotypically true breeding accession $M$. acuminata ssp. burmannicoides Calcutta 4 (Crouch et al. 1998a). This suggests that Calcutta 4 may not be appropriate as a tester genotype in genetic studies unless homozygosity can be demonstrated for the loci being examined.

\section{Diagnostics}

Development of rapid and sensitive techniques for the identification and detection of banana pathogens, particularly viruses, has been pursued in order to facilitate germplasm movement. While enzyme-linked immunosorbent assays (ELISA) have been developed for the three most widespread viruses [cucumber mosaic virus (CMV), banana streak virus (BSV), and banana bunchy top virus (BBTV)], these tests are often not sufficiently sensitive to detect low-titre infections and are complicated by the occurrence of serological diversity among virus isolates. A triple antibody sandwich (TAS-) ELISA for BSV detection has been developed (Ndowora and Lockhart 1998). Immunosorbent electron microscopy (ISEM) is much more reliable, but its wider application for indexing large numbers of samples is limited by labour, time and equipment requirements. Specific oligonucleotide primers have been developed for use in PCR-based methods of BSV detection (Lockhart and Olszewski 1993). Likewise, an immunocapture (IC-) PCR method has consistently amplified BSV (G. Thottappilly, IITA, unpub. data). This sensitive assay is easy and suitable for handling many samples. Further improvement of PCR protocols for BSV detection is ongoing.

\section{Current development of molecular breeding at IITA}

The International Institute of Tropical Agriculture (IITA) is committed to the application of biotechnology techniques to assist the investigation, genetic enhancement, and phytosanitary testing of its mandated crops. In vitro techniques have been routinely used at IITA for a considerable time. This includes the rescue of hybrid embryos from interploidy crosses in cowpea (Vigna unguiculata (L.) Walp.) and Musa breeding, in vitro germplasm conservation of cassava (Manihot esculenta Crantz), yams (Dioscorea spp.) and Musa, and somatic embryogenesis. IITA extended its commitment to research across the field of biotechnology in 1987 by establishing the Biotechnology Unit, the first phase of which was completed at its headquarters at Ibadan (Nigeria) in 1990 and the second phase in 1994. This research unit was established with the primary role of identifying, introducing and adapting new techniques that could strengthen ongoing activities. In addition to research, the unit plays an important role in training of African scientists in the techniques of this new field and acting as a bridge for the flow of useful techniques to African national agricultural research systems. The application of DNA marker technology at IITA was expanded in 1995 by the establishment of a molecular biology facility in the IITA High Rainfall Station at Onne (southeastern Nigeria).

The utilization of DNA markers at IITA has been assigned a high priority and all the major DNA marker assays are being applied for germplasm characterization, linkage mapping and molecular breeding. Plantain improvement was nominated as the model system for developing molecular breeding at IITA. This reflects the unique problems and opportunities in Musa breeding, including the long generation time and high space requirement of the crop, and the nascent development of plantain breeding. Theoretical and practical considerations concerning the nature of the crop and the application of molecular breeding in an infrastructurally limited environment warranted emphasis on PCR-based assays. For this reason, emphasis has been placed on the use of microsatellites which have become the marker of choice in model systems elsewhere. A collaborative venture between IITA and the United States Department of Agriculture (USDA) has cloned more than $300 \mathrm{~A}$ and $\mathrm{B}$ genome microsatellites for this purpose. Initial utilization of these markers has facilitated important insights into current breeding schemes, the genetic structure of important breeding accessions and the fingerprinting of registered improved hybrids (Crouch et al. 1998a, b; Ortiz et al. 1998).

Initial studies towards the development of marker-aided breeding in Musa at IITA have focused on characters which are primary early selection criteria, difficult to score or expressed late in the growth season. With the current emphasis on breeding triploid hybrids, the putatively oligogenic character of parthenocarpy has become a primary selection criterion which has a relatively low frequency in current breeding populations. Clearly, the ultimate potential of molecular breeding lies in assisting the selection of quantitative traits with low heritability. However, parthenocarpy is an ideal character for the initiation of MAS as genetically it is relatively simple yet its early selection would have a dramatic influence on breeding efficiency. Pragmatically, we do not expect that the initiation of molecular breeding in tropical crop improvement programs will be a simple procedure. Thus, through preliminary emphasis on this character it is hoped that logistical problems concerning the development and application of MAS will be quickly resolved. The experience gained in this endeavour should then facilitate more speedy application of MAS to quantitative traits.

Microsatellite markers are extremely effective and appropriate tools for molecular breeding but are expensive and time consuming to develop. In contrast, AFLP markers can be generated rapidly and efficiently but are not highly appropriate to routine screening of large breeding populations. For this reason a collaborative venture was established with scientists at the University of Gent (Belgium) to develop a system based on the conversion of AFLP markers to traditional PCR-based markers.

\section{Germplasm characterization}

Molecular genetic analysis offers a precise means of formulating taxonomic, phylogenic and heterotic groupings which may be of considerable value for identifying duplicate accessions, defining core collections, and for developing efficient breeding schemes. There are a number of reports of molecular genetic characterization of representatives of 
diverse groups within the Musa germplasm (reviewed above). However, little work has been carried out to intensively characterize the diversity within germplasm groups. For this reason, extensive RAPD analysis has been carried out on the majority of the more than 100 West African plantain landraces held in IITA's Musa collection. The results of this analysis indicate that most plantain landraces have a very high level of genetic similarity to one another (J.H. Crouch, IITA, unpub. data). This supports the suggestion that this germplasm evolved through somatic mutation of a very small number of progenitors introduced into Africa (Horry et al. 1997).

\section{Predicting the breeding value of parental genotypes}

The use of DNA marker analysis for predicting the breeding value of parental genotypes has been successful in certain systems but not in others. SSRLP analysis of Musa breeding populations and their parental genotypes has been compared with more traditional pedigree characterization data. However, within the tested germplasm, there was no correlation between hybrid similarities based on SSRLP and pedigree relationships (Tenkouano et al. 1998). Analysis of a range of breeding populations, particularly including those from diverse parents, must now be completed to clarify the value of this approach in Musa breeding strategies.

\section{Marker assisted selection for simply inherited characters}

Some of the most important characters to the Musa breeder have been reported to have an oligogenic epistatic basis (Ortiz 1995). One of the most important of these is the presence or absence of parthenocarpy. Around half of the several thousand secondary triploid hybrids annually established in early evaluation field trials at IITA are found to be non-parthenocarpic. A candidate SSRLP marker for parthenocarpy has been identified and its selective power is currently being tested (Crouch et al. 1998b). Clearly, application of this marker for screening new hybrid genotypes at the tissue culture stage could have a dramatic effect on the efficiency of the breeding program. Regulated suckering has been one of the primary selection criteria during the development of tetraploid hybrids and this character must be maintained in secondary triploid hybrids. Vigorous but regulated sucker growth is an important requisite for perennial productivity. This character is well expressed in bananas but not plantains, yet it is reported to have a simple genetic basis (Ortiz 1995). Candidate markers for apical dominance (the physiological basis for inhibition of sucker development) have been identified and its selective power is currently being confirmed (J.H. Crouch et al., unpub. data). Early flowering is also a key selection criteria in Musa breeding as it enhances perennial productivity (Ortiz and Langie 1997; De Cauwer and Ortiz 1998). Moreover, tetraploid hybrids tend to have shorter cycling periods than their parental landraces (Vuylsteke et al. 1993). Maintaining yield whilst reducing cycling time would be a most beneficial approach. For this reason, candidate markers have been identified for time to flowering (J.H. Crouch et al., unpub. data).

\section{Hybrid fingerprinting}

DNA fingerprinting for cultivar identification has been achieved with the use of short synthetic DNA probes specific for simple sequence repeats (Bhat et al. 1995). However, approaches based on hybridization protocols are not well suited to large scale routine screening. For this reason, SSRLP assays are also being used for the fingerprinting of IITA's Musa hybrids. By combining the banding patterns generated by two primers, it has been possible to formulate unique fingerprints for each of the registered tetraploid hybrids (J.H.Crouch et al. unpub. data). A similar procedure was followed in order to fingerprint secondary triploid hybrids derived from these tetraploid hybrids. In this case, a single primer was identified which could generate unique fingerprints for four hybrids which have been registered in the public domain (Ortiz et al. 1998). Comparable analysis using RAPD failed to identify a similar level of polymorphism (J.H. Crouch, unpub. data).

\section{Outlook}

The limited genetic and cytogenetic knowledge for many tropical crops has delayed their genetic improvement. The application of molecular biology techniques has the potential to speed-up the breeding of these crops. For example, identification of molecular markers linked to genes enhancing yield, particularly those with large effects explaining a significant percentage of the phenotypic variation in the reference population, will allow Musa breeders to select parents based on their genotype, rather than phenotype. Moreover, DNA markers may unleash the potential of wild and landrace genetic resources by enhancing their utilization in breeding programs. Recently, a small number of conventional genetic markers (black Sigatoka resistance, fruit parthenocarpy and ploidy) have been reported to explain up to $80 \%$ of the quantitative variation in plantain yield (Ortiz et al. 1997). DNA markers linked to these conventional genetic marker loci for black Sigatoka resistance and fruit parthenocarpy may improve the efficiency of genetic enhancement of yield in bananas and plantains.

\section{Genetic transformation}

The potential contribution of genetic engineering in crop improvement has been confounded because this technology has been highly popularized (and vilified) and its potential glamourized by individuals with a vested interest. Transformation has often been seen as a means to grossly simplify the complex nature of plant breeding and sustainable agriculture (Simoens and Van Montagu 1995; Simmonds 1997). Genetic transformation targets are often limited by the scarcity of useful genes, the lack of understanding of the energetic cost associated with the insertion of certain genes, and of the complex gene interactions that influence the most important quantitative traits in plants. Hence, it is essential to clearly define occasional and realistic targets for genetic engineering that can be included within innovative Musa breeding programs. However, government regulations may be a major obstacle for the release of transformed Musa cultivars. Furthermore, public acceptance of transgenic genotypes may become the most important hurdle for Musa biotechnologists and breeders to overcome. We believe that the aim of genetic engineering should be to put unique, important genes into 
elite germplasm for subsequent use in conventional Musa breeding. Currently, virus resistance (to BSV and BBTV) seems to be the most appropriate target to investigate the usefulness of transgenic methods in Musa improvement.

\section{Diagnostics for crop protection}

DNA markers have many applications in the investigation and genetic improvement of tropical crops. The sensitivity of PCR-based analysis is also revolutionizing many aspects of the diagnosis and study of crop diseases. Molecular marker technology has already been used to characterize diversity of fungal Musa pathogens (Johanson and Jeger 1993; Carlier et al. 1994). It is likely that these studies will lead to improved diagnostic tests for these important pathogens.

\section{Molecular cytogenetics and aneuploid stocks}

For many crops, particularly tropical vegetatively propagated crops, the current genetic and cytogenetic knowledge limits crop improvement efforts. Molecular markers are contributing to a substantial resurgence of progress in these areas through linkage studies and molecular cytogenetic analysis. A and B genome specific markers have recently been generated for molecular cytogenetic (Osuji et al. 1997a) and molecular marker (J.H. Crouch, unpub. data) investigations. These new tools will facilitate precise genomic characterization of natural and hybrid germplasm and determine the level of differentiation between $\mathrm{A}$ and $\mathrm{B}$ genomes. In addition, such analyses will allow more detailed study of the segregation and recombination of $\mathrm{A}$ and $\mathrm{B}$ genome chromosomes during interploidy and interspecific crosses involving allopolyploid Musa accessions. Furthermore, molecular cytogenetic analysis also offers the potential of generating genetic stocks through the characterization of aneuploids. Such genetic stocks have proven powerful resources for chromosome manipulation in genetic analysis and crop improvement in other systems. However, these stocks were developed using cytogenetic analyses based on precise karoytypes. Unfortunately, cytogenetic techniques are not sufficiently developed in Musa to support such activities. Nevertheless, molecular markers have been proposed and utilized to direct the development of genetic stocks (substitution and aneuploid series) in certain crops prior to the generation of well defined karyotypes (Howell et al. 1996). Aneuploid plants have been generated in Musa from 3x-2x crosses (Osuji et al. 1997b), suggesting that the development of genetic stocks could easily be integrated into a Musa breeding program. Thus, the identification of chromosome-specific markers from core linkage maps of A and B genomes will enable directed development of such genetic stocks. Once generated, these stocks could be maintained in vitro and would provide a considerable resource for fundamental and applied Musa researchers.

\section{Germplasm management and DNA fingerprinting}

The intensive molecular genetic characterization of plantain landraces based on RAPD analysis presents a firm basis for a number of interesting developments. Genotype fingerprints so far generated can now be compared with analyses of local germplasm in order to estimate the efficiency of germplasm collections to represent and conserve rare alleles in the genepool. Musa accessions have been named in different dialects resulting in numerous synonyms and homonyms
(Shanmugavelu et al. 1992). Molecular genetic analysis of indigeneous germplasm will give a more accurate reflection of which accessions are being cultivated where and how closely this relates to the names given to these genotypes by farmers in various locations. In addition, it will be most useful to compare the classification based on RAPD analysis with analysis based on SSRLP and AFLP. This type of comparative analysis will give considerable insight into the value of each assay for germplasm characterization in the Musa genus. As the different assays distinguish different types of genetic variation, such comparative analysis may also give considerable insights into the evolution of plantains and bananas. Likewise, a marker for a specific mutant genotype in dessert bananas has already reported (Damasco et al. 1996) and it is likely that markers will be generated in due course for a range of serious mutant genotypes in cooking bananas and plantains. These will be crucial tools in Musa germplasm conservation and large-scale micropropagation programs. The use of molecular markers for cultivar fingerprinting also offers great potential for safe guarding breeders rights. In addition, it offers a very precise means for public Musa breeders to assess the extent to which their new cultivars are being grown and thereby assess the impact of their crop improvement programs.

\section{Assisted breeding with molecular markers}

Theoretically, MAS offers clear advantages in genetic terms over traditional selection in many circumstances. However, the potential of the technique is currently limited by the facilitating techniques and technology. Nevertheless, the increasingly widespread application of PCR-based diagnostics and marker assisted breeding together with the resultant falling of associated costs are a clear indication of the present confidence in the potential of DNA marker technology. In many instances, DNA markers will be a vital link in the development of knowledge-led breeding schemes. However, there remains a considerable need for parallel progress in the understanding of genotype-by-environment interaction and the influence of epigenetic mechanisms. Nevertheless, even with the current level of understanding, the application of DNA marker technology is likely to facilitate the attainment of new objectives in crop research and genetic improvement that have proven difficult to achieve using classical techniques. For example, highly precise MAS approaches demand linkage information. However, the generation of highly relevant and precise linkage maps is not routinely achievable in Musa due to the triploid nature of the crop and of the current breeding populations. Thus, the simultaneous application of two diverse approaches is being pursued to facilitate the generation of appropriate linkage maps:

(a) Linkage mapping based on diploid relatives and extrapolation to the polyploid crop. Thus, large diploid populations have been generated from plantain-banana interploidy crosses and from crosses between $M$. balbisiana accessions. These will be used for the development of traditional linkage maps, and,

(b) Polyploid mapping based on single dose markers in populations derived from crosses between heterozygous tetraploid and diploid genotypes. In this way, it may be possible to generate linkage maps of current Musa breeding populations which are allotetraploid products of interploidy crosses. The accuracy and practical value 
of such linkage maps will be determined through comparative analysis with diploid maps and the current breeding populations.

\section{Conversion of AFLP markers}

AFLP marker bands have been cloned and converted to allele-specific PCR markers in model systems with simple genomes. However, the reliability with which the same approach can be applied in complex polyploids, such as Musa, remains to be demonstrated. Thus, as a test system, AFLP analysis of Musa breeding populations has been initiated through a collaborative project between IITA and the University of Gent (Belgium). It is hoped that AFLP markers tightly linked to loci influencing parthenocarpy will be identified. These amplification products may then be cloned and sequenced. The sequence information can then be used to design allele-specific PCR primers that could be used to screen current plantain breeding populations in order to test the value of this approach.

\section{Genetic-aided analysis with DNA markers}

Many important agronomic characters have a polygenic basis and are highly influenced by the environment. Multienvironment trials of Musa mapping populations are, therefore, proposed across agroecological zones. This will allow detailed analysis of quantitative trait loci (QTL) contributing to important agronomic characters that are difficult to score in the field (including root system factors) and characters expressed late in the growth season (including yield and post-harvest traits). This will also facilitate analysis of the importance of QTL-by-environment interaction as has been achieved in other systems (Jansen et al. 1995). Likewise, genetic analysis of resistance to black Sigatoka and other important pests and diseases in diverse germplasm could enable the identification of markers for distinct sources of resistance genes. MAS could then be used for directing the pyramiding of resistance genes as a strategy for generating potential durable resistance to specific pest and diseases.

\section{Progressive heterosis}

In addition to resistance to black Sigatoka, heterosis in bunch yield has been a major component of the success of tetraploid hybrids (Vuylsteke et al. 1993). The scope for further genetic improvement of Musa is huge in comparison to most of the cereal crops (de Vries et al. 1967). It is expected that heterosis will be an important aspect of this increased productivity. Nevertheless, the genetic basis of heterosis must be determined in Musa in order to design appropriate breeding schemes (Ortiz 1997). Comparative genotyping and yield assessment of breeding populations derived from full-sib, half-sib and unrelated crosses should determine the relative importance of broad genetic diversity of parental genotypes as opposed to the accumulation of favorable alleles in progeny genotypes. Markers for favorable alleles or genome diversity will then be developed as appropriate. If genomic diversity is considered to be the major basis of heterosis in Musa, then fingerprinting of parental genotypes may be sufficient to predict progeny performance. Conversely, the manipulation of favourable alleles would require MAS of progeny populations.

\section{Marker assisted gene introgression}

Introgression of genes for pest and disease resistance from wild germplasm has been and is likely to continue to be a crucial aspect of the Musa improvement schemes. Thus, it is likely that breeders will wish to eliminate large portions of the donor parent genome. Marker assisted gene introgression offers an extremely efficient means of precisely identifying rare segregants with the required genome compositions. This can be achieved in a generalized way by combining phenotypic selection for the character of interest with random molecular genetic screening of the genome. However, maximum efficiency of this approach would rely on the generation of a consensus core linkage map.

\section{Map-based cloning of genes underlying important agronomic characters}

The cloning of genes underlying important agronomic characters offers to revolutionize progress in plant research and breeding, particularly in the area of pest and disease resistance. A significant number of diverse disease resistance genes have now been cloned which function against viruses, bacteria and fungi. This work has facilitated the testing of strategies for the development of transgenic plants resistant to insect pests, viral, bacterial and fungal diseases, and nematodes. The cloning of several plant disease resistance genes in model plant species was facilitated by chromosome walking from closely associated markers on dense linkage maps. The study and utilization of these genes from model plant systems is likely to influence the genetic improvement of a large range of crops. Parthenocarpy is as important for Musa as apomixis may be for field crops. An SSRLP marker for parthenocarpy has already been identified in Musa. It is proposed that dense linkage mapping of this genomic region could be carried out using AFLP analysis followed by mapbased cloning. A similar strategy could also be followed for the map-based cloning of genes contributing to dwarfism and albinism in plantains and bananas. The cloning of these genes would be of great value to both fundamental and applied researchers of many crops.

\section{The future of biotechnology in the genetic enhancement of Musa}

All available tools must be employed to meet the challenges of sustainable agriculture and food security in the tropics. Reseachers are investigating new biotechniques that may have great potential in the genetic enhancement of plantains and bananas (Table 1). However, biotechnology should be integrated along with other techniques already available in current Musa improvement programs. New scientific partnerships, strategic research alliances, and joint ventures between public and private breeders must be explored to successfully achieve this goal. Today, biotechnology provides to banana and plantain improvement programs clean and fast multiplication of genotypes via micropropagation, diagnostics to ensure virus-tested germplasm, and genetic markers for assisted selection and gene introgression.

\section{Acknowledgements}

Musa research at IITA has benefited from grants from several donors through the Consultative Group on 
International Agricultural Research, particularly the Belgian

Administration for Development Cooperation.

Table 1. Status of biotechnology for the genetic enhancement of the Musa genome

Technique

Micropropagation

in vitro germplasm conservation

in vitro germplasm exchange

Virus-free plant by meristem culture

Embryo culture

Somatic embryogenesis

in vitro screening

Protoplast fusion

Anther culture

Cryopreservation

Somaclonal variation

Transgenic technology

Recombinant DNA for diagnostics

Biochemical markers

DNA flow cytometry

DNA-aided taxonomy

DNA fingerprinting for cultivar identification

DNA-assisted genetic Analysis

DNA marker selection

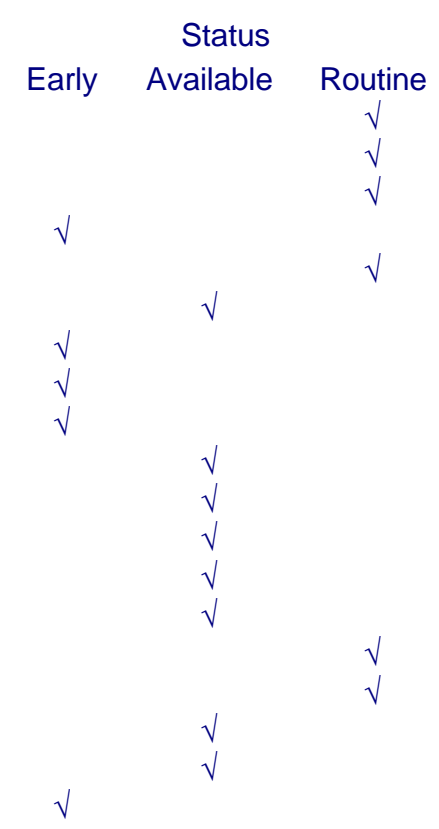

\section{References}

Banerjee, N. and De Langhe, E. (1985). A tissue culture technique for rapid clonal propagation and storage under minimal growth conditions of Musa (banana and plantain). Plant Cell Report 4:351-354.

Baurens, F.C., Noyer, J.L., Lanaud, C. and Lagoda, P.J.L. (1997). Sequence tagged site markets to draft the genomic structure of the banana chloroplast. Fruits 52:247-259.

Bhat, K.V., Bhat, S.R. and Chandel, K.P.S. (1992a). Survey of isozyme polymorphism for clonal identification in Musa. I. Esterase, acid phosphatase and catalase. Journal of Horticultural Science 67:501-507.

Bhat, K.V., Bhat, S.R. and Chandel, K.P.S. (1992b). Survey of isozyme polymorphism for clonal identification in Musa. II. Peroxidase, superoxide dismutase, shikimate dehydrogenase and malate dehydrogenase. Journal of Horticultural Science 67:737-744.

Bhat, K.V., Bhat, S.R., Chandel, K.P.S., Lakhanpaul, S. and Ali, S. (1995). DNA fingerprinting of Musa cultivars with oligodeoxyribonucleotide probes specific for simple sequence repeat motifs. Genetic Analysis Biomedical Engineering 12:45-51.

Bhat, K.V., Jarret, R.L. and Liu, Z.-W. (1994). RFLP characterization of Indian Musa germplasm for clonal identification and classification. Euphytica 80:95-103.

Bhat, K.V. and Jarret, R.L. (1995). Random amplified polymorphic DNA and genetic diversity in Indian Musa germplasm. Genetic Resources and Crop Evolution 42:107118.
Bhat, K.V., Lakhanpaul, S., Chandel, K.P.S. and Jarret, R.L. (1997). Molecular markers for characterization and identification of genetic resources of perennial crops. In: Molecular Genetic Techniques for Plant Genetic Resources. W.G. Ayad, T. Hodgkin, A. Jaradat and V.R. Rao. Rome, International Plant Genetic Resources Institute. pp.107-118

Bonner, J.W., Warner, R.M. and Brewbaker, J.L. (1974). A chemosystematic study of Musa cultivars. HortScience 9:325-328.

Bosque-Pérez, N.B., May, G.D. and Arntzen, C.J. (1998). Applicability of an Agrobacterium system for the transformation of Musa species with diverse genomic constitution and ploidy level. Acta Horticulturæ, in press.

Carlier, J., Mourichon, X., González de León, D., Zapater, M.F. and Lebrun, M.H. (1994). DNA restriction fragment length polymorphisms in Mycosphaerella species that cause banana leaf spot diseases. Phytopathology 84:751-756.

Carreel, F., Fauré, S., González de León, D., Lagoda, P.J.L., Perrier, X., Bakry, F., Tezenas du Montcel, H., Lanaud, C. and Horry, J.P. (1994). Evaluation de la diversité génétique chez les bananiers diploídes (Musa sp.). Genetic, Selection, Evolution 26:125s-136s.

Cox, E.A., Stotzky, G. and Goos, R.D. (1960). In vitro culture of Musa balbisiana Colla embryos. Nature 185:403404.

Cronauer, S.S. and Krikorian A.D. (1984). Rapid multiplication of bananas and plantains by in vitro shoot tip culture. HortScience 19:234-235. 
Crouch, H.K., Crouch, J.H., Jarret, R.L., Cregan, P.B. and Ortiz, R. (1998a). Segregation of microsatellite loci from haploid and diploid gametes in Musa. Crop Science 38:211217.

Crouch, J.H., Crouch, H.K., Ortiz, R. and Jarret, R.L. (1997). Microsatellite markers for molecular breeding of Musa. InfoMusa 6(1):5-6.

Crouch, J.H., Ortiz, R., Crouch, H.K., Ford-Lloyd, B.V., Howell, E.C., Newbury, H.J. and Jarret, R.L. (1998b). Utilization of molecular genetic techniques in support of plantain and banana improvement. Acta Horticulturæ, in press.

Damasco, O.P., Graham, G.C., Henry, R.J., Adkins, S.W., Smith, M.K. and Godwin, I.D. (1996). Random amplified polymorphic DNA (RAPD) detection of dwarf off-types in micropropagated Cavendish (Musa spp. AAA) bananas. Plant Cell Reports 16:118-123.

Dantas, J.L.L., Shepherd, K., dos S. Soares Filho, W., Cordeiro, Z.J.M., de Oliveira e Silva, S. and Silva Souza, A. (1993). Citogenetica e melhoramento genetico da bananeira (Musa spp.). Documentos EMBRAPA-CNMPF 48. 61pp.

De Cauwer, I. and Ortiz, R. (1998). Analysis of the genotype $\mathrm{x}$ environment interaction in Musa trials. Experimental Agriculture 34. In press.

de Vries, A.C., Ferwerda, J.D., Flach, M. (1967). Choice of food crops in relation to actual and potential production in the tropics. Netherlands Journal of Agricultural Sciences 15:241-248.

Dhed'a, D., Dumortier, F., Panis, B., Vuylsteke, D. and De, Langhe E. (1991). Plant regeneration in cell suspension cultures of the cooking banana cv. 'Bluggoe' (Musa spp, ABB group). Fruits 46: 125-135.

Diekmann, M. and Putter, C.A.J. (eds.) (1996). Musa spp. (2nd edition). FAO/IPGRI Technical Guidelines for the Safe Movement of Germplasm No. 15. Rome, Food and Agriculture Organization of the United Nations/International Plant Genetic Resources Institute.

Dolezel J., Dolezelova, M. and Novak, F.J. (1994). Flow cytometric estimation of nuclear DNA amount in diploid bananas (Musa acuminata and M. balbisiana). Biologia Plantarum 36:351-357.

Drew, R.A., Moisander, J.A. and Smith, M.K. (1989). The transmission of banana bunchy-top virus in micropropagated bananas. Plant Cell, Tissue and Organ Culture 16:187-193.

Drew, R.A. and Smith, M.K. (1990). Field evaluation of tissue-cultured bananas in south-eastern Queensland. Australian Journal of Experimental Agriculture 30: 569-574.

Escalant, J.V. and Teisson, C. (1989). Somatic embryogenesis and plants from immature zygotic embryos of the species Musa acuminata and Musa balbisiana. Plant Cell Reports 7:665-668.

Escalant J.V., Paduscheck C., Babeau J., and Teisson C. (1993). Somatic embryogenesis in triploid banana cultivars.
In: Breeding Banana and Plantain for Resistance to Diseases and Pests. J. Ganry. Montpellier, CIRAD and INIBAP. pp. 313-316.

FAO (1998). http://apps.fao.org/lim500 /nphwrap.pl?Production.Crops.Primary\&Domain=SUA

Fauré, S., Noyer, J.L., Horry, J.P., Bakry, F., Lanaud, C. and González de León, D. (1993). A molecular marker-based linkage map of diploid bananas (Musa acuminata). Theoretical and Applied Genetics 87:517-526.

Gawel, N.J. and Jarret, R.L. (1991a). Cytoplasmic genetic diversity in banana and plantain. Euphytica 52:19-23.

Gawel, N.J. and Jarret, R.L. (1991b). Chloroplast DNA restriction fragment length polymorphisms (RFLP's) in Musa species. Theoretical and Applied Genetics 81:783-786.

Gawel, N.J., Jarret, R.L. and Whittemore, A.P. (1992). Restriction fragment length polymorphism (RFLP)-based phylogenetic analysis of Musa. Theoretical and Applied Genetics 84:286-290.

Horry, J.P. and Jay, M. (1988). Distribution of anthocyanins in wild and cultivated banana varieties. Phytochemistry 27:2667-2672.

Horry, JP, Ortiz, R., Arnaud, E., Crouch, J.H., Ferris, R.S.B. Jones, D.R., Mateo, N., Picq, C. and Vuylsteke, D. (1997). Banana and plantain. In: Biodiversity in Trust. D. Fuccillo, L. Sears and P. Stapleton. Cambridge, Cambridge University Press. pp. 67-81.

Howell, E.C., Newbury, H.J., Swennen, R.L., Withers, L.A. and Ford-Lloyd, B.V. (1994). The use of RAPD for identifying and classifying Musa germplasm. Genome 37:328-332.

Howell P.M., Marshall D.F., and Lydiate, D.J. (1996). Towards developing intervarietal substitution lines in Brassica napus using marker-assisted selection. Genome 39:348-358.

Israeli, Y., Lahav, E. and Reuveni, O. (1995). In vitro culture of bananas. In: Bananas and Plantains. S. Gowen. London, Chapman \& Hall. pp. 147-178.

Jarret, R.L., Bhat, K.V., Cregan, P., Ortiz, R. and Vuylsteke, D. (1994). Isolation of microsatellite DNA markers in Musa. InfoMusa 3:3-4.

Jarret, R.L., Gawel, N., Whittemore, A. and Sharrock, S. (1992). RFLP-based phylogeny of Musa species in Papua New Guinea. Theoretical and Applied Genetics 84:579-584.

Jarret, R.L. and Litz, R. (1986). Isozymes as genetic markers in bananas and plantains. Euphytica 35:537-539.

Jansen, R.C., Ooijen, J.W. van, Stam, P., Lister, C. and Dean,C. (1995). Genotype by environment interaction in genetic mapping of multiple quantitative trait loci. Theoretical and Applied Genetics 91:33-37 
Jenny, C., Carreel, F. and Bakry, F. (1997). Revision of banana taxonomy: 'Klue Tiparot' (Musa sp.) reclassified as a triploid. Fruits 52:83-91.

Johanson, A. and Jeger, M.J. (1993). Use of PCR for detection of Mycosphaerella fijiensis and M. musicola, the causal agent of Sigatoka leaf spots in banana and plantain. Mycological Research 97:670-674.

Kaemmer, D., Afza, R., Weising, K., Kahl, G. and Novak, F.J. (1992). Oligonucleotide and amplification fingerprinting of wild species and cultivars of banana (Musa spp.). Bio/Technology 10:1030-1035.

Kaemmer, D., Fischer, D., Jarret, R.L., Baurens, F.C., Grapin, A., Dambier, D., Noyer, J.L., Lanaud, C., Kahl, G. and Lagoda, P.J.L. (1997). Molecular breeding in the genus Musa: a strong case for STMS marker technology. Euphytica 96:49-63.

Lagoda, P.J.L., Noyer, J.L., Dambier, D., Baurens, F.C. and Lanaud, C. (1995). Abundance and distribution of SSR (simple sequence repeats) in the Musaceae family: Microsatellite markers to map the banana genome. In: Proc. of the FAO/IAEA International Symposium on Induced Mutations and Molecular Techniques for Crop Improvement. Vienna, FAO/IAEA. pp. 287-295.

Lanaud, C., Tezenas du Montcel, H., Jolivot, M.P., Glaszmann, J.C. and Gonzalez de Leon, D. (1992). Variation in ribosomal gene spacer length among wild and cultivated bananas. Heredity 68:148-156.

Lebot, V., Aradhya, K.M., Manshardt, R. and Meilleur, B. (1993). Genetic relationships among cultivated bananas and plantains from Asia and the Pacific. Euphytica 67:163-175.

Lockhart, B.E.L. and Olszewski, N.E. (1993). Serological and genomic heterogeneity of banana streak badnavirus: implications for virus detection in Musa germplasm. In: Breeding Banana and Plantain for Resistance to Diseases and Pests. J. Ganry. Montepellier, CIRAD/INIBAP. pp. 105-113.

Ma, S.S. (1988). Somatic embryogenesis and plant regeneration from cell suspension culture of banana. In: Proceedings Conference on Applications of Horticultural Plant-tissue Breeding. pp. 181-188 (in Chinese, with English summary).

May, G., Afza, R., Mason, H., Wiecko, A., Novak, F. and Arntzen, C. (1995). Generation of transgenic banana (Musa acuminata) plants via Agrobacterium-mediated transformation. Bio/Technology 13:486-492.

\section{NCGR (1998).}

htpp:/www.ncgr.org/gpi/oddysey/agbio/foods.html

Ndowora, T.S.C. and Lockhart, B.E.L. (1998). Development of a serological assay for detecting serologically diverse banana streak virus isolates. Acta Horticulturæ.In press.

Novak, F.J., Afza, R., van Duren, M., Perea-Dallos, M., Conger, B.V. and Xiaolang, T. (1989). Somatic embryogenesis and plant regeneration in suspension cultures of dessert (AA and AAA) and cooking (ABB) bananas (Musa spp.). Bio/Technology 7:154-159.
Ortiz, R. (1995). Musa genetics. In: Bananas and Plantains. S. Gowen. London, Chapman and Hall. pp. 84-109.

Ortiz, R. (1997). Secondary polyploids, heterosis, and evolutionary crop breeding for further improvement of the plantain and banana (Musa spp. L.) genome. Theoretical and Applied Genetics 94:1113-1120.

Ortiz, R. and Langie, H. (1997). Path analysis and ideotypes for plantain breeding. Agronomy Journal 89:988-994.

Ortiz, R., and Vuylsteke, D. (1996). Recent advances in Musa genetics, breeding and biotechnology. Plant Breeding Abstracts 66:1355-1363.

Ortiz, R., Craenen, K. and Vuylsteke D. (1997). Ploidy manipulations and genetic markers as tools for analysis of quantitative trait variation in progeny derived from triploid plantains. Hereditas 126:255-259.

Ortiz, R., Vuylsteke, D.R., Crouch, H.K. and Crouch, J.H. (1998). TM3x: triploid black sigatoka-resistant Musa hybrid germplasm. HortScience 33. In press.

Osuji, J.O., Harrison, G., Crouch, J.H. and Heslop-Harrison, J.S. (1997a). Identification of the genomic constitution of Musa L. genotypes (bananas, plantains and hybrids) using molecular cytogenetics. Annals of Botany 80:787-793.

Osuji, J.O., Vuylsteke, D. and Ortiz, R. (1997b). Ploidy variation in hybrids from interploid $3 x \times 2 x$ crosses in Musa. Tropicultura 15. In press.

Panis, B., Van Wauwe, A. and Swennen, R. (1993). Plant regeneration through direct somatic embryogenesis from protoplasts of banana (Musa spp.). Plant Cell Reports 12: 403-407.

Panis, B., Totté, N., Van Nimmen, K., Withers, L. and Swennen R. (1996). Cryopreservation of banana (Musa spp.) meristem cultures after preculture on sucrose. Plant Science 121:95-106.

Remy, S., Francois, I., Schoofs, H., Panis, B., Cammue, B., Swennen, R. and Sagi, L. (1998). Genetic transformation as a technology to create disease resistance in banana. Acta Horticulturæ. In press.

Robinson, J.C., Fraser, C. and Eckstein, K. (1993). A field comparison of conventional suckers with tissue culture banana planting material over three crop cycles. Journal of Horticultural Science 68:831- 836.

Rowe, P. and Rosales, F.E. (1996). Bananas and plantains. In: Fruit Breeding. Vol. 1: Tree and Tropical Fruits. J. Janick and J. Moore. New York, John Wiley. pp. 167-211.

Sagi, L., Panis, B., Remy, S., Schoofs, H., De Smet, K., Swennen, R. and Cammue, B. (1995). Genetic transformation of banana (Musa spp.) via particle bombardment. Bio/Technology 13:481-485.

Sagi, L., Remy, S., Panis, B., Swennen, R. and Volckaert, G. (1994). Transient gene expression in electroporated banana (Musa spp., cv. 'Bluggoe', ABB group) protoplasts isolated 
from regenerable embryogenic cell suspensions. Plant Cell Reports 13: 262-266.

Shanmugavelu, K.G., Aravindakshan, K. and Sathiamoorthy, S. (1992). Banana Taxonomy, Breeding and Production Technology. London, Metropolitan Book Co. Ltd.

Simmonds N.W. (1962). Evolution of the Bananas. London, Longmans.

Simmonds, N.W. (1997). Pie in the sky. Tropical Agriculture Association Newsletter, June 1997:1-5.

Simmonds, N.W. and Shepherd, K. (1955). The taxonomy and origins of the cultivated bananas. Journal Linnean Society London Bot. 55:302-312.

Simoens, C. and Van Montagu, M. (1995). Genetic engineering in plants. Human Reproduction Update 1:523542.

Smith, M.K. (1988). A review of factors influencing the genetic stability of micropropagated bananas. Fruits 43:219223.

Smith, M.K. and Drew, R.A. (1990a). Current applications of tissue culture in plant propagation and improvement. Australian Journal of Plant Physiology 17:267-289.

Smith, M.K. and Drew, R.A. (1990b). Growth and yield characteristics of dwarf off-types recovered from tissuecultured bananas. Australian Journal of Experimental Agriculture 30:575-578.

Tenkouano, A., Crouch, J.H., Crouch, H.K. and Ortiz, R. (1998). Genetic diversity, hybrid performance, and combining ability for yield in Musa germplasm. Euphytica. In press.

Van den houwe, I., De Smet, K., Tezenas du Montcel, H. and Swennen, R. (1995). Variability in storage potential of banana shoot cultures under medium term storage conditions. Plant Cell, Tissue and Organ Culture 42: 269-274.

Van Duren, M., Morpurgo, R., Dolezel, J., and Afza, R. (1996). Induction and verification of autotetraploids in diploid banana (Musa acuminata) by in vitro techniques. Euphytica 88: 25-34.

Vuylsteke, D. (1989). Shoot-tip culture for the propagation, conservation, and exchange of Musa Germplasm. Practical Manuals for Handling Crop Germplasm In Vitro 2. Rome, International Board for Plant Genetic Resources.

Vuylsteke, D. (1998). Field performance of banana micropropagules and somaclones. In: Somaclonal Variation and Induced Mutation in Crop Improvement. S.M. Jain, D.S. Brar and B.S. Ahloowalia. Dordrecht, Kluwer Academic Publishers. pp. 219-231.

Vuylsteke, D. and Ortiz, R. (1996). Field performance of conventional vs. in vitro propagules of plantain (Musa spp., AAB group). HortScience 31:862-865.
Vuylsteke, D., Schoofs, J., Swennen, R., Adejare, G., Ayodele, M. and De Langhe, E. (1990a). Shoot-tip culture and third-country quarantine to facilitate the introduction of new Musa germplasm into West Africa. Plant Genetic Resources Newsletter 81/82:5-11.

Vuylsteke, D., Swennen, R. and De Langhe, E. (1990b). Tissue culture technology for the improvement of African plantains. In: Sigatoka Leaf Spot Diseases of Bananas. R.A. Fullerton and R.H. Stover. Montpellier, INIBAP. pp. 316337.

Vuylsteke, D., Swennen, R. and De Langhe, E. (1991). Somaclonal variation in plantains (Musa spp, AAB group) derived from shoot-tip culture. Fruits 46:429-439.

Vuylsteke, D., Swennen, R. and Ortiz, R. (1993). Development and performance of black sigatoka-resistant tetraploid hybrids of plantain (Musa spp., AAB group). Euphytica 65:33-42.

Vuylsteke, D., Ortiz, R., Ferris, S. and Swennen R. (1995). 'PITA-9': a black-sigatoka-resistant hybrid from the 'False Horn' plantain gene pool. HortScience 30:395-397.

Vuylsteke, D., Swennen, R. and De Langhe, E. (1996). Field performance of somaclonal variants of plantain (Musa spp., AAB group). Journal of the American Society of Horticultural Science 121:42-46.

Vuylsteke, D., Ortiz, R., Ferris, R.S.B. and Crouch, J.H. (1997). Plantain improvement. Plant Breeding Reviews 14:267-320.

Weising, K., Khan, F., Kaemmer, D., Fischer, D. and Kahl, G. (1996). Microsatellite-based molecular markers and their application for genome analysis in Musa cultivars and wild species. In: Report of the 1st FAO/IAEA Research Coordination Meeting on Cellular Biology and Biotechnology for Creation of New Useful Banana Genotypes, 20-24 Nov. 1995, Vienna, Austria. Vienna, FAO/IAEA. pp. 57-59. 